\title{
Políticas de apoio à indústria de petróleo e gás no Brasil: um estudo das ações públicas para o desenvolvimento da cadeia de valor *
}

\author{
Ricardo José dos Santos \\ Ana Paula Macedo de Avellar ${ }^{* * *}$
}

\begin{abstract}
Resumo
Em razão do seu caráter estratégico para a economia e para a política, a Indústria de Petróleo e Gás Natural foi protagonista, sobretudo a partir do ano de 1970, de uma intensa atuação do Estado brasileiro. Nesse contexto, o objetivo deste artigo é analisar as políticas de Desenvolvimento da Cadeia de Valor da Indústria de Petróleo e Gás Natural entre os anos de 1999 e 2014, com destaque para os programas Repetro, Política de Conteúdo Local e Programa BNDES P\&G. Utiliza-se o método qualitativo do "Postulado de Coerência", baseado na relação dos componentes, OrganizaçõesMétodos-Propósitos com os elementos específicos de cada política. Assim, o método tem o intuito de auxiliar na avaliação da coerência entre os componentes supracitados e os resultados desejados. Conclui-se que as políticas estudadas apresentam incoerências que impedem o correto desenvolvimento das ações públicas e o alcance dos resultados necessários para o aumento da competitividade das empresas nacionais atuantes nesse setor.
\end{abstract}

Palavras-chave: Políticas Públicas; Política Industrial; Estrutura Industrial; Cadeia de Fornecedores da IP\&G; "Postulado de Coerência".

\begin{abstract}
Policies to support the oil and gas industry in Brazil: a study of public actions to develop the value chain.

Because of its strategic importance to the economy and politics, the Oil and Gas Industry played a central role, especially from the 1970s onwards, in an intense involvement of the Brazilian state. In this context, the objective of this article is to analyze the Value Chain Development Policy of the Oil and Natural Gas Industry between 1999 and 2014, especially the Repetro programs, Local Content Policy and the BNDES O\&G Program. A qualitative method of "Coherence Postulate", based on the interrelation of three components, Organizations-Methods-Purposes with specific elements of each policy, is used. Thus, the method is intended to assist in evaluating the consistency between the components and the planned policy results. It is concluded that the policies are inconsistent and do not make it possible to develop public actions and achieve the results required to increase the competitiveness of domestic enterprises.
\end{abstract}

Keywords: Public Policy; Industrial Policy; Industrial Structure; Supply Chain of the O\&G Industry; "Coherence Postulate".

JEL L52, L78, O38.

${ }^{*}$ Artigo recebido em 10 de setembro de 2015 e aprovado em 25 de agosto de 2017. Os pensamentos e ideias expressos neste trabalho não refletem necessariamente aqueles das instituições as quais os autores estão vinculados. Os autores gostariam de agradecer os pareceristas anônimos da Revista Economia \& Sociedade pelos comentários e contribuições. Os eventuais erros e omissões são de inteira responsabilidade dos autores. Os autores gostariam ainda de agradecer o apoio da Coordenação de Aperfeiçoamento de Pessoal de Nível Superior (Capes) [Processo: BEX 5796/15-6]. Os autores agradecem o apoio do CNPq e Fapemig.

** Professor da Universidade Federal de Mato Grosso do Sul, Campo Grande, MS, Brasil. E-mail: ricardo.jose@ufms.br.

**** Professora da Universidade Federal de Uberlândia, Uberlândia, MG, Brasil. E-mail: anaavellar@ufu.br. 


\section{Introdução}

A trajetória da Indústria de Exploração e Produção de Petróleo e Gás (IP\&G), no Brasil, é relevante, longa e um complexo objeto de estudo.

O estudo da IP\&G no Brasil é relevante, em virtude da capacidade dessa indústria de promover crescimento e desenvolvimento econômico, social e científico. O caminho transcorrido pela IP\&G nacional é longo, pois os primeiros passos datam ainda do século XIX, quando em 1897 foram realizadas as primeiras perfurações exploratórias em Bofete, São Paulo. A IP\&G brasileira é complexa por envolver uma grande diversidade de atores e instituições políticas, econômicas e da sociedade civil.

Nesse sentido, quais os motivos levam ao fato de que, ainda hoje, as empresas brasileiras representem papel secundário na maior parte dos segmentos e subsegmentos da IP\&G? Mais do que isso, por que as políticas de fomento direcionadas ao setor não são capazes de fazer com que o desenvolvimento da cadeia nacional de fornecedores seja alcançado?

Desse modo, este artigo tem como objetivo, a partir de uma análise qualitativa, analisar as Políticas de Desenvolvimento da Cadeia de Valor direcionadas à IP\&G do Brasil entre os anos de 1999 e 2014. Para isto, o trabalho é estruturado a partir de três componentes metodológicos, a saber: as Organizações; os Métodos e os Propósitos (O-M-P). Tais componentes são os elementos fundamentais que dão sustentação à metodologia utilizada, denominada de "Postulado de Coerência".

Assim, adota-se a hipótese de que o desenho complexo da estrutura de mercado desse setor, associado a uma frágil coordenação entre O-M-P, cria obstáculos ao desenvolvimento e à implantação de políticas públicas capazes de promover o aumento da competitividade e da participação das empresas nacionais na cadeia da IP\&G.

O trabalho está organizado em três seções, além desta introdução e de uma seção para considerações finais. A primeira seção busca dar suporte à metodologia de análise, a partir dos apontamentos feitos por De Negri (2011) acerca das empresas que compõem a cadeia da IP\&G. Desse modo, será apresentada a configuração da estrutura dessa indústria para o período de 1999 a 2007. Na segunda seção, são expostas as ações públicas de Desenvolvimento da Cadeia de Valor para a IP\&G adotadas no Brasil no período de 1999 a 2014. Nesse sentido, são evidenciadas as diretrizes gerais do Repetro, da Política de Conteúdo Local, e do Programa BNDES P\&G. Na terceira seção, apresenta-se a metodologia para o desenvolvimento da análise das políticas elencadas. Partindo da premissa de que as políticas devem apresentar uma necessária relação entre O-M-P, aplicam-se os componentes do "Postulado da Coerência" às ações públicas estudadas. Por fim, são expostas as 
conclusões obtidas das análises das políticas selecionadas, apresentando-se uma resposta ao objetivo geral e à hipótese levantada.

\section{Estrutura da cadeia de exploração e produção da indústria de petróleo e gás}

Nesta seção, apresenta-se a configuração da IP\&G nos segmentos primários de Exploração e Produção (E\&P) para o período de 1999 a 2007 . A opção pelos anos indicados é justificada por compreender um espaço temporal marcado por alterações de ordem institucional e estratégica para a história recente da IP\&G no Brasil.

É nesse intervalo de tempo que se consolida a mudança do marco regulatório sob a Lei n. 9.478 de 1997, a partir da qual são implantadas importantes políticas para o setor, e se anuncia a descoberta de reservas provadas de óleo na província do Pré-Sal. Portanto, é nesse contexto que se inicia um novo estágio de impulso à IP\&G no Brasil e a busca pelo desenvolvimento de uma cadeia competitiva de fornecedores locais.

A proposta é evidenciar, a partir da descrição da estrutura dessa indústria, o desafio que as Políticas de Desenvolvimento da Cadeia de Valor se propõem a enfrentar. Nesse sentido, pretende-se corroborar a visão de De Negri (2011) em relação às empresas que conformam a cadeia da IP\&G. Segundo o autor, essa cadeia é formada por:

(i) Empresas grandes, em virtude de sua maior margem para negociação de preço e habilidade para o cumprimento dos serviços;

(ii) Empresas com mais tempo no mercado, que já tiveram oportunidade de criar uma reputação e que já foram testadas em diferentes condições;

(iii) Empresas que possuem mão de obra mais qualificada e que têm, portanto, mais condições de implementar inovações de processo e de produto, além de disporem de mais versatilidade para se adaptar a novas tecnologias;

(iv) Empresas que exportam mais e que, portanto, estão expostas a maiores níveis de exigências; e

(v) Empresas com mais cientistas e, portanto, mais aptas a desenvolver e assimilar novas tecnologias (De Negri, 2011, p. 94).

Além disso, a cadeia da IP\&G é composta por um número significativo de ramos industriais, além de uma rede bastante complexa de relações com outros setores da economia ${ }^{1}$. Cada uma das atividades que estruturam a IP\&G tem propósitos distintos. Assim, o segmento de E\&P, objeto de estudo neste trabalho,

(1) Entende-se aqui, como cadeia da IP\&G, o conjunto de empresas que produzem bens e/ou prestam serviços, direta ou indiretamente, para as atividades de exploração, desenvolvimento, produção de petróleo e gás, refino, petroquímica, transporte, estocagem e distribuição de derivados (Araújo; Mendes; Costa, 2012). 
representa a etapa inicial dessa atividade, incluindo desde a prospecção geofísica para a identificação das jazidas até a produção e o armazenamento do óleo extraído.

Segundo De Negri (2011), a predominância de empresas de grande porte na cadeia da IP\&G pode ser explicada a partir da capacidade que possuem para a negociação de preço, além do fato de que apresentam capacitações para o cumprimento dos serviços especializados necessários à consolidação dos investimentos no setor.

A primeira justificativa apresentada para explicar o tamanho das firmas da cadeia da IP\&G pode ser observada em Steindl (1983). Segundo o autor, o aumento da margem de lucro em razão da redução dos custos proporciona uma taxa de acumulação interna maior. Essa taxa, direcionada a novas inversões produtivas, promoveria um aumento na capacidade de produção. Assim, as firmas ampliariam sua capacidade de negociação em virtude do aumento na margem de lucro e da possibilidade de utilização da guerra de preços para excluir firmas menores e mais fracas, a fim de ganhar espaço para sua própria expansão (Steindl, 1983).

O segundo argumento apresentado por De Negri (2011) para justificar o protagonismo das grandes empresas nessa indústria pode ser comparado à ideia apresentada por Teece e Pisano (1994), de que as firmas acumulam competências a partir dos processos, trajetórias e posicionamentos que adotam, e isso proporcionaria às empresas o desenvolvimento de capacitações dinâmicas.

Corroborando as observações anteriores, conforme Bain \& Company e Tozzini Freire Advogados (2009), essa configuração também pode ser explicada pelos seguintes fatores: (i) redefinição e foco do negócio principal das Oil Companies (OCs); (ii) otimização do uso do capital por parte das OCs; e (iii) benefícios percebidos de compartilhamento de custos e benefícios entre os segmentos de E\&P e as OCs.

No primeiro ponto, vê-se uma tendência muito comum no período estudado: o processo de desverticalização e terceirização de atividades por parte das OCs que direcionaram seus esforços ao gerenciamento de reservas e da produção. $\mathrm{O}$ segundo fator passa pela necessidade das OCs de reduzirem o montante de capital a ser imobilizado em ativos, o que inviabilizaria a contratação de serviços relevantes como os serviços sísmicos, frente à maturidade de diversas jazidas. Por fím, fornecedores de bens e serviços têm vantagens de custos ao oferecerem seus serviços para diferentes operadoras que reduzem significativamente seus investimentos em atividades específicas e ambas ganham com o 
"compartilhamento" de atividades, sobretudo, no que diz respeito ao desenvolvimento de tecnologias avançadas ${ }^{2}$.

Essa conjunção de fatores faz com que as empresas líderes em seus segmentos sejam, em primeiro lugar, empresas de grande porte. Assim, em termos da cadeia da IP\&G, as dez empresas com maiores receitas capturavam em 2007, $35,11 \%$ dos ganhos, sendo que a líder mundial, a gigante Schlumberger ${ }^{3}$, detinha de forma isolada $8,57 \%$ da receita global da cadeia, o equivalente a US\$ 19.9 bilhões (ver Gráfico 1).

\section{Gráfico 1}

Participação das 10 maiores fornecedoras de bens e serviços na receita global da IP\&G (em 2007)

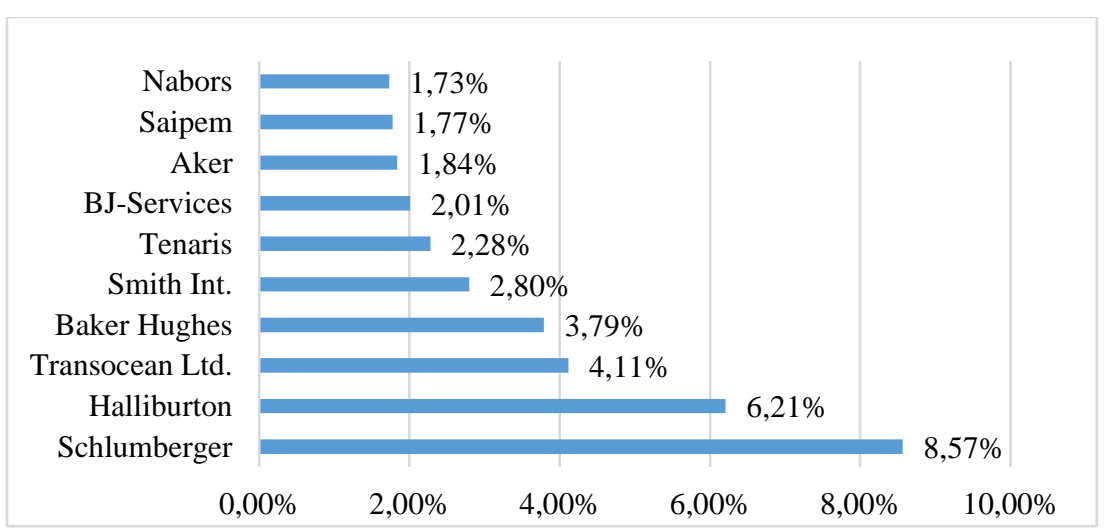

Fonte: Elaboração própria a partir de Bain \& Company e Tozzini Freire Advogados (2009).

Em segundo lugar, essas empresas são capazes de reter parcelas significativas das receitas dos mercados em que atuam. Portanto, como exposto no Gráfico 2, além dos segmentos primários da IP\&G serem dominados por empresas de grande porte, são também mercados com alto nível de concentração. Em 2007, aproximadamente $52 \%$ da receita global da cadeia estava vinculada a apenas trinta empresas.

(2) Ao analisar o crescimento significativo das empresas da cadeia da IP\&G, sobretudo, a partir dos anos de 1990, observa-se que está relacionado com a retomada dos investimentos das Oil Companies (OCs) após um longo período de baixa de preços. No período de 1999 a 2007, a participação de fornecedoras contratadas nas atividades de E\&P se manteve significativamente elevada, com uma média anual de 78;56\% do gasto total nessas atividades. Como resultado, a cadeia de fornecedores foi beneficiada com o aumento da receita em $230 \%$ ao final de oito anos.

(3) Fundada em Paris (França) em 1926, a Schlumberger é a maior empresa prestadora de serviços para a IP\&G. A empresa emprega aproximadamente 126 mil funcionários de mais de 140 nacionalidades em 87 países. 


\section{Gráfico 2}

Concentração de Mercado das Empresas "Top 5" dos Seguimentos Primários da Cadeia da IP\&G (\% da Receita em 2007)

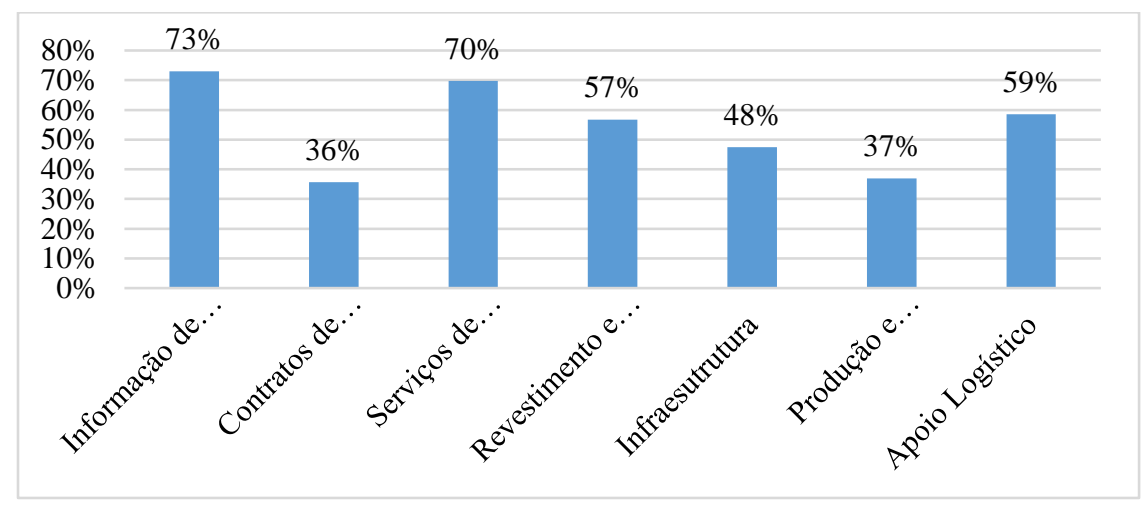

Fonte: Elaboração própria a partir de Bain \& Company e Tozzini Freire Advogados (2009).

Ainda, há elevada concentração de mercado proveniente das altas barreiras de entrada em diversos segmentos e subsegmentos como Equipamentos de Revestimento e Cimentação; Revestimento e Instalação de Tubulação de Produção; Leasing de Floating Production Storage and Offloading (FPSO); Apoio Aéreo, entre outros. Nesses subsegmentos, em 2007, tinha-se de três a seis empresas controlando entre $60 \%$ e $80 \%$ do mercado mundial ${ }^{4}$.

A tendência de concentração e manutenção de barreiras se confirmou nos anos seguintes. Em 2013, a cadeia da IP\&G registrou o valor recorde de US\$ 271 bilhões em operações de Fusão e Aquisição (F\&A). Não menos importante, a média entre os anos de 2007 e 2013 foi de US\$ 173 bilhões em atos de concentração (OGFJ, 2015) $)^{5}$.

Conforme De Negri (2011), as empresas que fazem parte da cadeia da IP\&G são firmas com larga experiência nesse mercado, predominantemente internacionalizadas ${ }^{6}$, atuando em diversos países produtores. Além disso, possuem mão de obra com maior nível de qualificação e, portanto, mais apta a desenvolver e adotar inovações de produto, serviço e processo produtivo.

(4) Nesse sentido, as empresas estabelecidas na IP\&G apresentam vantagens de diferentes naturezas sobre as empresas potenciais entrantes. Para aprofundar a discussão sobre barreiras de entrada, ver Bain (1969) e Gilbert (1989).

(5) Penrose (2006) aponta que a análise das relações entre as fusões, o surgimento e a persistência de firmas dominantes tem como um de seus problemas de estudo a importância das fusões como meio para manter uma posição dominante previamente adquirida.

(6) Para Hitt, Duane e Robert (2005), a internacionalização pode ocorrer em virtude de mercados domésticos saturados que impõem limites ao crescimento de uma determinada empresa; da busca das empresas por melhor rentabilidade, uma vez que os custos operacionais e em P\&D serão diluídos; além de obter economias de escala e escopo e aproveitamento de vantagens locacionais. 
Com relação à trajetória histórica das empresas, segundo Penrose (2006), os impactos de fatores externos em relação a uma firma, dependem, sobremaneira, das condições internas decorrentes de sua história e de decisões tomadas ao longo de sua existência. Nesse sentido, para Baptista (2000, p. 8) "a história passada da firma, materializada em seus ativos e capacitações, condiciona fortemente a sua trajetória futura de expansão". Assim, a competência de uma empresa não se resume apenas em sua eficiência produtiva, é preciso que o aprendizado obtido com as rotinas ofereça suporte para a implantação de inovações; portanto, a inovação tecnológica como diferencial produtivo e competitivo, mas que demanda um ambiente adequado para seu pleno desenvolvimento.

Corroborando o apontamento feito por De Negri (2011) e as ideias de Penrose (2006) e Baptista (2000), é possível observar, a partir das informações contidas no Gráfico 3, que as empresas líderes dos segmentos e subsegmentos da cadeia da IP\&G apresentam significativa experiência nessa indústria. Desse modo, a tradição e o aprendizado administrativo, institucional, cultural, técnico e tecnológico, são fatores importantes a serem considerados pelas potenciais entrantes nessa cadeia produtiva.

\section{Gráfico 3}

Média de Tempo no Mercado das Empresas "Top 5" dos Seguimentos Primários da Cadeia de Fornecedores da IP\&G (em anos)

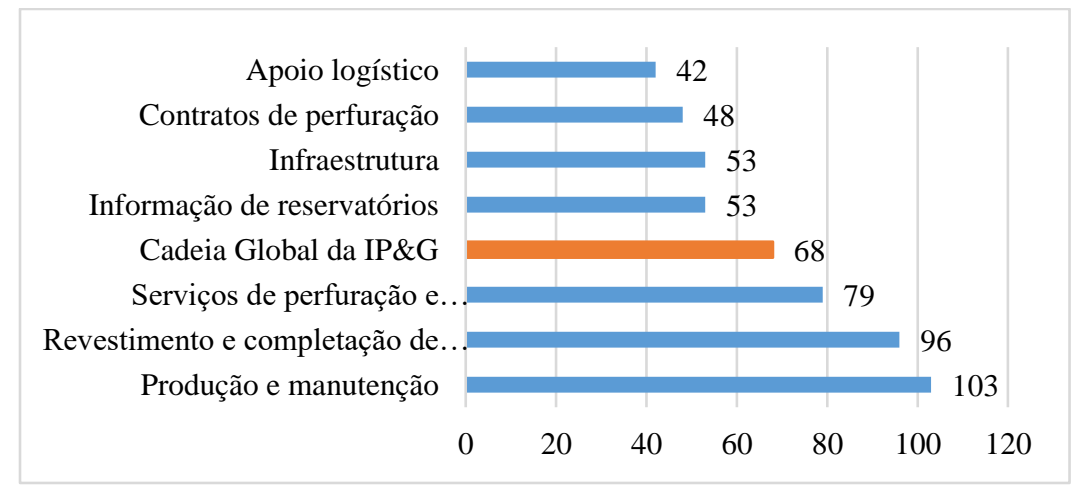

Fonte: Elaboração própria.

Desse modo, conforme apontam Teece e Pisano (1994), as oportunidades tecnológicas que estão postas para as empresas não seriam completamente exógenas como determina a abordagem tradicional, o que significa dizer que, como fora 
analisado anteriormente, a capacitação tecnológica da empresa depende de sua trajetória ${ }^{7}$, dos ativos e das oportunidades criadas internamente ${ }^{8}$.

Além disso, dada a natureza das atividades na cadeia da IP\&G, até mesmo tradicionais companhias integradoras mantêm altos volumes de investimento em pesquisa e desenvolvimento (P\&D) com vistas a sustentar suas posições de liderança na indústria. Como pode ser observado no gráfico 4, a seguir, empresas como Schlumberger, Baker Hughes; Weatherford e Halliburton, as maiores representantes dos segmentos em que atuam, eram também líderes em volume de recursos direcionados para P\&D no ano de 2007.

\section{Gráfico 4}

Investimentos em P\&D de Empresas Selecionadas da Cadeia da IP\&G - 2007 (em US\$ milhões)

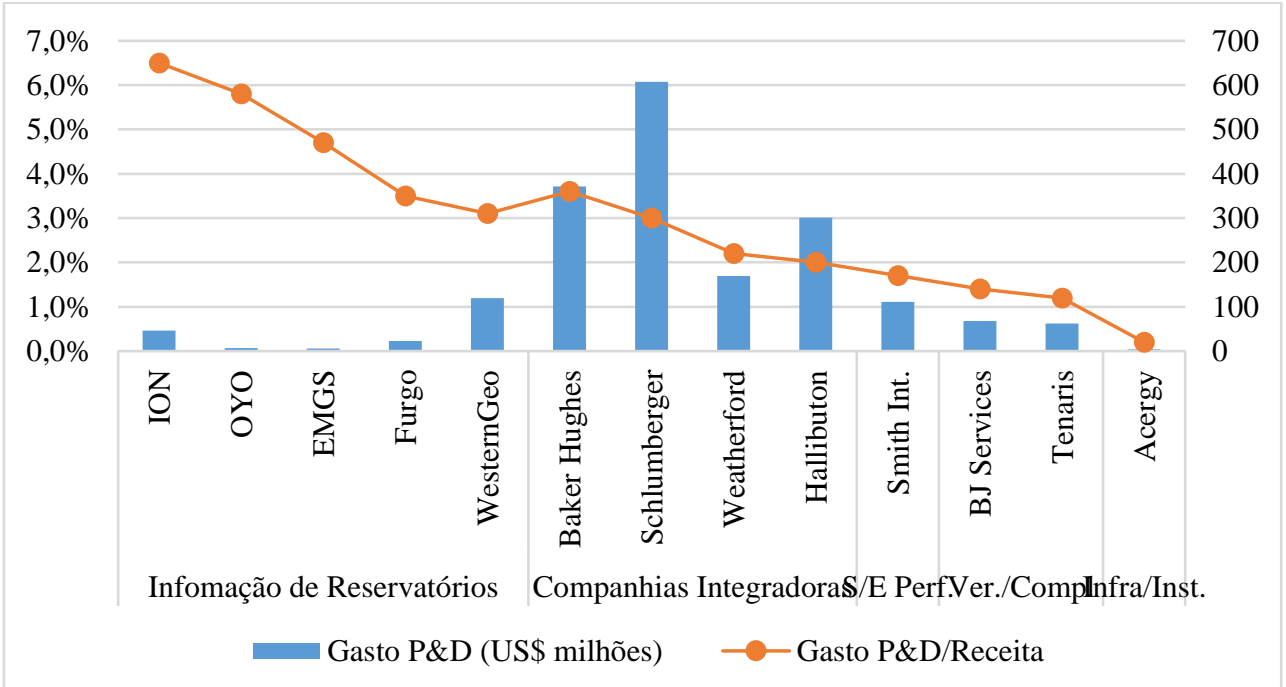

Fonte: Elaboração própria a partir de Bain \& Company e Tozzini Freire Advogados (2009).

Desse modo, sobretudo para produção offshore em águas profundas e ultraprofundas, exige-se das empresas que atuam nos elos da cadeia crescentes níveis de certificação e qualidade para seus produtos e serviços. Nessas condições, as firmas realizam um considerável empenho em busca de eficiência e segurança em suas operações. Para isso, incorrem em significativos investimentos em inovação, com o objetivo de aperfeiçoar ou introduzir no mercado novos serviços e

(7) Teece e Pisano (1994), assim como Nelson e Winter (2005), advogam que a trajetória da empresa é função de sua conduta passada - path dependence -, isto é, o progresso de uma empresa é função da trajetória atual e futura, condicionada pela trajetória passada.

(8) Evidencia-se, portanto, o caráter cumulativo do aprendizado tecnológico, que influencia na direção do progresso técnico (Rosenberg, 2006). De acordo com Tigre (1998, p. 93) “a aprendizagem é cumulativa e coletiva (no âmbito da firma) e depende fundamentalmente de rotinas organizacionais codificadas ou tácitas". 
equipamentos para E\&P de petróleo e gás $(\mathrm{P} \& \mathrm{G})$ em ambientes com alto grau de complexidade (Araújo; Mendes; Costa, 2012).

Assim, fica clara a relevância do investimento em P\&D para o segmento de Informação de Reservatório. O gasto em relação à receita das empresas apresenta os valores mais elevados dentre todos os segmentos da cadeia. Isso se explica pelas características das novas pesquisas exploratórias em campos de difícil aferição das jazidas.

Dada a importância da P\&D e da capacidade inovativa das firmas nessa indústria, cabe ressaltar que, para além do tempo de atividade no setor, outro fator a ser considerado é a origem das empresas líderes dos segmentos primários. Como pode ser observado no Gráfico 5, os países de origem das empresas líderes, com exceção da China, apresentam altos Índices de Desenvolvimento Humano (IDH). Dessa forma, são países que oferecem acesso a ensino de qualidade em todos os níveis de formação, suas populações apresentam maior média de escolaridade; possuem universidades e centros de pesquisa de excelência, além de competências em atividades complementares àquelas inerentes à IP\&G.

\section{Gráfico 5}

Participação por país de origem no "Top 5" dos segmentos primários da cadeia da IP\&G (em 2007)

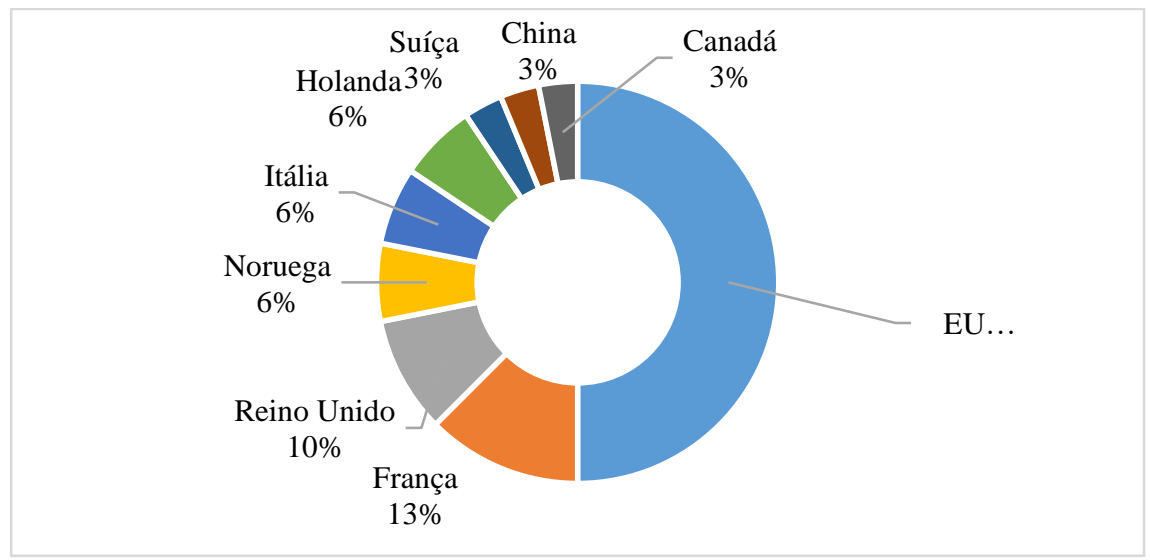

Fonte: Elaboração própria a partir de Bain \& Company e Tozzini Freire Advogados (2009).

No entanto, como essas empresas possuem elevado nível de internacionalização, atuam em diversos países produtores que apresentam baixa oferta de mão de obra qualificada, assim, sobretudo, na América Latina e África, os fornecedores da cadeia da IP\&G, quando não importam mão de obra, acabam por assumir o papel de financiar a qualificação e o treinamento de seus funcionários.

Considerando as informações apresentadas até aqui, é possível perceber que as empresas líderes dos segmentos primários da cadeia da IP\&G se alinham a importantes aspectos apontados por Dunning (1993) em seu Paradigma Eclético da 
Produção Internacional. Desse modo, as firmas possuem fatores específicos de propriedade, a partir de suas capacitações, sendo que lançam mão de suas trajetórias históricas e de altos investimentos em P\&D para garantir uma inserção internacional em bases competitivas. Além disso, conseguem aferir vantagens locacionais e superar limitações dos países de destino ao realizar a correta leitura do tipo de internacionalização mais adequada para os mercados-alvo.

Assim, é possível elencar alguns pontos característicos da cadeia da IP\&G para o período de 1999 a 2007. Em primeiro lugar, o espaço temporal delimitado apresenta uma forte recuperação da capacidade de investimento das OCs após mais de uma década de preços baixos para o barril de petróleo e consequente retração da atividade exploratória e produtiva. A retomada das atividades do segmento de E\&P foi acompanhada pela intensificação da prática de contratação de empresas fornecedoras de bens e serviços de classe mundial.

Em segundo lugar, a aceleração das atividades não abriu espaço para o surgimento de novos players importantes entre os líderes dos segmentos e subsegmentos primários da cadeia da IP\&G. As empresas líderes de todos os segmentos fazem parte dessa indústria há décadas e, em muitos casos, haviam sido, em sua origem, empresas pioneiras nessa indústria. Portanto, mesmo as firmas surgidas de processos de F\&A, tinham em sua conformação atores já consolidados na IP\&G.

Em terceiro lugar, o período foi marcado pela intensificação das atividades de $\mathrm{P} \& \mathrm{D}$, sobretudo, nos seguimentos de exploração, em virtude dos desafios técnicos impostos pelos novos campos em águas profundas e ultraprofundas. Nesse sentido, empresas originárias de países com oferta de mão de obra qualificada, universidades, centros de pesquisa e capacidade de financiamento, puderam explorar tais vantagens para consolidar sua condição no mercado ou promover uma mudança de posicionamento.

Portanto, o desenho da IP\&G para o período de 1999 a 2007 confirma os apontamentos feitos por De Negri (2011) com relação às empresas e à estrutura de mercado deste setor. A seguir, apresenta-se as Políticas de Desenvolvimento da Cadeia de Valor adotadas no Brasil com o intuito de fomentar a ampliação da participação das empresas nacionais nesta indústria e, portanto, permitir algum grau de enfrentamento ao panorama identificado.

\section{Políticas de desenvolvimento da cadeia de valor para a IP\&G no Brasil}

A política setorial $^{9}$ está vinculada à ideia de uma rede de relações interfirmas e interindústrias associada aos ganhos de aprendizado e inovatividade. Ainda que a política seja concebida com o objetivo de afetar o comportamento das

(9) O recorte setorial como orientador da elaboração de política industrial e tecnológica é explorado na literatura por Malerba (2003, p. 362). Segundo esse autor, a abordagem de sistema setorial é uma importante alternativa para a concepção de política, por considerar o locus de interseção de numerosas redes geradoras de tipos específicos de conhecimentos do setor. 
firmas e da indústria na qual se insere, o seu foco deve ser a cadeia produtiva (Baptista, 2000). Essa visão é corroborada por Cimoli et al. (2009) ao afirmarem que um papel crucial das políticas é o de impactar a capacidade dos atores da cadeia de superar grandes defasagens tecnológicas.

Para Ferraz, De Paula e Kupfer (2002) esse tipo de política, para promover as mudanças desejadas, precisa contemplar duas premissas. Em primeiro lugar, a redução dos custos de produção em virtude do aprendizado acumulado ao longo do tempo, o que diminuiria o hiato de produtividade entre a indústria nacional e os players internacionais. Em segundo lugar, é importante ter em conta o horizonte temporal da intervenção. Nesse sentido, o mesmo deve ser limitado em virtude do risco de se criar uma indústria nacional superprotegida, ineficiente e pouco competitiva.

Segundo Cimoli et al. (2009) é preciso aprender sobre as circunstâncias em que a proteção à indústria jovem leva a uma indústria local forte, e as condições sob as quais ela é perniciosa ao desenvolvimento de uma indústria competitiva. Assim, o resultado desejado deve ser pautado mais pelo desempenho competitivo, a partir da inserção internacional de produtos e empresas, e menos pelo aumento da capacidade produtiva e do grau de nacionalização da produção. $\mathrm{O}$ contrário levaria a uma política de substituição de importações incapaz de promover o avanço competitivo necessário ao desenvolvimento industrial.

A partir do exposto, apresentam-se as Políticas de Desenvolvimento da Cadeia de Valor para a IP\&G, analisadas neste trabalho: Repetro, Política de Conteúdo Local e BNDES P\&G.

\subsection{Repetro}

Em um panorama de abertura da IP\&G com o objetivo de atrair empresas estrangeiras para o país, foi criado em 1999 o regime aduaneiro especial de exportação e de importação de bens destinados às atividades de pesquisa e de lavra das jazidas de petróleo e de gás natural (Repetro). O Repetro suspendeu impostos de importação e os demais tributos federais na admissão temporária de qualquer bem para as atividades de pesquisa e lavra.

O regime aduaneiro especial de exportação e de importação de bens destinados às atividades de pesquisa e de lavra das jazidas de petróleo e de gás natural (Repetro) foi instituído em 2 de setembro de 1999 pelo Decreto 3.161, o qual estabelecia sua vigência até 31 de dezembro de 2005. No ano de 2001, sua vigência foi alterada para 31 de dezembro de 2007, e, por fim, em 2004, o regime especial teve sua vigência mais uma vez prorrogada até 31 de dezembro de 2020 (Araujo; Mendes; Costa, 2012, p. 233).

Nota-se que o Repetro é menos uma política de fomento à cadeia da IP\&G e mais um tipo de instrumento complementar ao que deveria ser um programa mais 
abrangente. No entanto, dadas suas características e o contexto em que foi criado, é elemento indispensável ao estudo da IP\&G no Brasil.

O novo regime aduaneiro previa: i) regime especial de admissão temporária aos bens exportados com saída ficta do território nacional; ii) o regime de drawback, na modalidade de suspensão do pagamento dos impostos incidentes, de matériasprimas, produtos semielaborados e partes e peças, para a produção de bens a serem exportados nos termos do inciso anterior; iii) concessão do regime especial de admissão temporária, quando se tratar de bens estrangeiros ou desnacionalizados que procedam diretamente do exterior (Receita Federal, 2014) ${ }^{10}$.

Os bens importados sob o Repetro têm um tempo limitado para permanecer dentro do território brasileiro, que corresponde ao prazo da concessão ou à vigência do contrato. Ao término do tempo de autorização de permanência no país, os bens devem ser: (i) reexportados; (ii) entregues à Fazenda Nacional; (iii) destruídos; (iv) transferidos para outro regime aduaneiro especial; ou (v) despachados para consumo (Receita Federal, 2014).

$\mathrm{O}$ repetro trouxe à $\mathrm{IP} \& \mathrm{G}$ um novo debate acerca do tipo de política e desenvolvimento industrial que se quer promover no Brasil. Neste sentido, o regime, como um instrumento eminentemente técnico, não oferece a subjetividade necessária para que seja um mecanismo includente. Ao contrário, suas normas, regras e exceções, fazem com que o regime apresente traços de seletividade.

\subsection{Política de conteúdo local}

O processo de abertura da economia e da indústria do petróleo, o fim das barreiras não tarifárias à importação, vide Repetro, e a dificuldade de acesso ao crédito em condições favoráveis, agravaram a situação das empresas brasileiras da cadeia da IP\&G, o que provocou uma crescente perda de competitividade e, claro, de oportunidades de negócios ${ }^{11}$.

(10) No entanto, desde que observados os dispositivos legais, os bens submetidos ao Repetro podem ser utilizados de forma compartilhada, para atender a outro contrato indicado no Ato Declaratório Executivo de habilitação. O uso compartilhado é vedado apenas no caso de o contrato original de prestação de serviços não possuir cláusula contemplando a exclusividade de utilização dos bens (Bain \& Company e Tozzini Freire Advogados, 2009).

(11) Isto pode ser observado por meio do significativo redirecionamento do suprimento da produção offshore para o mercado externo. Conforme Rappel $(2003,2007)$ dentre as quinze primeiras plataformas flutuantes de produção adquiridas pela Petrobras no período pós-abertura, somente três foram construídas no Brasil, com investimentos de US\$ 600 milhões; enquanto doze foram contratadas a estaleiros no exterior (Cingapura, Holanda, Portugal, Espanha, China, Coreia e Canadá), a um montante de US\$ 2.3 bilhões, com participação nacional pouco expressiva, variando de zero a 20\%. Deste modo, em que pese à argumentação de Moreira e Correia (1997) acerca dos possíveis benefícios da abertura comercial para os setores industriais, percebeu-se logo que seria necessário mais que exposição à concorrência estrangeira para dinamizar a indústria nacional da cadeia da IP\&G. 
Com o objetivo de corrigir a patente disparidade de condições de competição no mercado de fornecimento de bens e serviços, no processo de licitação para concessão de novas áreas para E\&P, a Agência Nacional do Petróleo, Gás Natural e Biocombustíveis (ANP) incluiu como critério de julgamento uma pontuação proporcional ao nível de compromisso com o Conteúdo Local (CL) nos projetos de investimento das participantes dos leilões. No entanto, nas quatro primeiras rodadas, entre 1999 e 2002, esse compromisso com o CL era voluntário, não havendo qualquer obrigação preestabelecida de que a futura concessionária adquirisse algum percentual mínimo de bens ou serviços brasileiros.

Para Fernández y Fernández (2013), essa flexibilidade era fundamental para manter a integridade do marco regulatório vigente. Na visão do autor, qualquer interferência mais incisiva ou exigência em relação à contratação mínima relacionadas ao CL poderiam ser lidas como uma política puramente protecionista.

$\mathrm{O}$ argumento do governo federal, naquele momento, era de que as normas para o CL deveriam ser uma ação de apoio e valorização da indústria nacional. Assim, a obrigatoriedade de um compromisso mínimo com fornecedores nacionais era encarada como um retrocesso às políticas de reserva de mercado praticadas em décadas anteriores. Além disso, a gestão federal, explicitamente alinhada às ideias neoliberais dominantes naquele período, acreditava que a obrigatoriedade feria as regras do mercado e se concretizaria como um desestímulo aos investidores internacionais.

Entretanto, com a vitória da oposição nas eleições presidenciais de 2002, e o redirecionamento da política energética, a partir do quinto leilão, em 2003, a ANP alterou a regra referente ao CL, exigindo um percentual variável de $30 \%$ a $70 \%$ de produtos e serviços nacionais (ver Quadro 1).

Quadro 1

Resumo do percentual de conteúdo local obrigatório nas rodadas da ANP

\begin{tabular}{|c|c|c|c|c|c|c|c|}
\hline \multicolumn{2}{|c|}{} & \multicolumn{2}{|c|}{ Águas Profundas } & Águas Rasas < 100 m & \multicolumn{2}{|c|}{ Terra } \\
\hline Rodada & Ano & $\begin{array}{c}\text { Explo- } \\
\text { ração }\end{array}$ & $\begin{array}{c}\text { Desenvol- } \\
\text { vimento }\end{array}$ & $\begin{array}{c}\text { Explo- } \\
\text { ração }\end{array}$ & $\begin{array}{c}\text { Desenvol- } \\
\text { vimento }\end{array}$ & $\begin{array}{c}\text { Explo- } \\
\text { ração }\end{array}$ & $\begin{array}{c}\text { Desenvol- } \\
\text { vimento }\end{array}$ \\
\hline 1 a 4 & $1999-2002$ & 0 & 0 & 0 & 0 & 0 & 0 \\
\hline 5 & 2003 & 30 & 30 & 50 & 60 & 70 & 70 \\
\hline 6 & 2004 & 30 & 30 & 50 & 60 & 70 & 70 \\
\hline 7 & 2005 & $37-55$ & $55-65$ & $51-60$ & $63-70$ & $70-80$ & $77-85$ \\
\hline 8 & 2006 & $37-55$ & $55-65$ & $51-60$ & $63-70$ & $70-80$ & $77-85$ \\
\hline 9 & 2007 & $37-55$ & $55-65$ & $51-60$ & $63-70$ & $70-80$ & $77-85$ \\
\hline 10 & 2008 & $37-55$ & $55-65$ & $51-60$ & $63-70$ & $70-80$ & $77-85$ \\
\hline 11 & 2013 & $37-55$ & $55-65$ & $51-60$ & $63-70$ & $70-80$ & $77-85$ \\
\hline
\end{tabular}

Fonte: ANP (2014). 
Segundo Rappel (2007), isso foi interpretado pelos atores da cadeia como uma retomada da política industrial para o setor, com o objetivo de ampliar as compras no mercado interno e reduzir a um patamar mínimo as importações de equipamentos e serviços de forma a aumentar a geração interna de emprego e fortalecer a indústria nacional.

Nesse caso, as operadoras vencedoras dos leilões se comprometiam, em contrato, ao cumprimento da obrigação de atingir um CL mínimo, global e individual, dos diversos subsistemas. Sendo que o não cumprimento dessas cláusulas implicaria em multas a serem estabelecidas pela ANP (Araújo; Mendes; Costa, 2012) ${ }^{12}$.

No mesmo campo do Repetro e da Política de Conteúdo Local tem-se, ainda, ações voltadas ao financiamento do investimento da cadeia da IP\&G. Neste sentido, o Programa BNDES P\&G se apresenta como uma das alternativas.

\subsection{Programa BNDES P\&G}

Na esteira da nova realidade que cerca a IP\&G no Brasil após o anúncio das reservas provadas na província do Pré-Sal, o Banco Nacional de Desenvolvimento Econômico e Social (BNDES) passou a acompanhar mais de perto a trajetória percorrida pelos segmentos dessa indústria e adotou políticas para se adaptar às mudanças. Tal acompanhamento tem sido facilitado pelo fato de o Banco ter assento no Programa de Mobilização da Indústria Nacional de Petróleo e Gás Natural (Prominp), bem como pelo fato de ter participado da comissão interministerial do Pré-Sal.

Dadas às perspectivas de produção na província do Pré-Sal e os impactos na cadeia produtiva do setor, o BNDES - em 2009 - promoveu alterações em seu arcabouço de apoio setorial para atender de forma mais adequada aos atores da IP\&G, com maior enfoque na cadeia de fornecedores de bens e serviços ${ }^{13}$.

Nesse sentido, o BNDES alterou sua estrutura organizacional criando, em 2010, o Departamento da Cadeia Produtiva de Petróleo e Gás, cujas atribuições compreendem tanto a participação no trabalho de articulação institucional, quanto às atividades relacionadas ao fomento e ao financiamento das empresas fornecedoras de bens e serviços da IP\&G.

(12) Assim como no caso do Repetro, o debate acerca da adoção de cláusulas de obrigatoriedade de CL nos contratos de concessão é polêmico e encontra defensores e detratores. Aqueles que têm uma postura contrária alegam que tais regras são, antes de tudo, prejudiciais ao desenvolvimento da exploração e da produção. Para eles, tal sistema torna a cadeia da IP\&G ineficiente e deixa o mercado nacional menos competitivo e atraente ao investidor privado. Os defensores da obrigatoriedade mínima de CL argumentam que tal estratégia força as empresas estrangeiras a nacionalizarem a sua produção, e que esses processos beneficiariam empresas locais de menor porte que ocupam o papel de subfornecedoras, além de favorecer o desenvolvimento de parcerias de produção e P\&D.

(13) Além disso, o banco buscou desenvolver mecanismos de aproximação com a indústria, associações de classe e órgãos do governo ligados ao segmento. 
Como desdobramento dessa nova estruturação, no segundo semestre de 2011, foi aprovada a criação do Programa de Apoio ao Desenvolvimento da Cadeia de Fornecedores de Bens e Serviços Relacionados ao Setor de Petróleo e Gás Natural (Programa BNDES P\&G), para o qual uma carteira de operações de financiamento foi constituída, facilitando o acesso ao crédito às micro, pequenas e médias empresas (MPMEs) e oferecendo condições de financiamento mais favoráveis, de forma a atender às necessidades da indústria (Araújo; Mendes; Costa, $2012)^{14}$.

Com vigência até 31 de dezembro de 2015, o programa tinha como objetivos (i) alavancar atividades de pesquisa, desenvolvimento e inovação; (ii) contribuir para o aumento de Conteúdo Local; (iii) garantir maior escala dos fornecedores; (iv) permitir a diminuição dos gargalos produtivos do setor. Ou seja, contribuir para o desenvolvimento da cadeia de fornecedores de bens e serviços relacionados à indústria de petróleo e gás natural.

Conforme BNDES (2014a), entre 2012 e maio de 2014, o BNDES P\&G, por meio do subprograma estruturante, contratou 32 projetos a um valor total de $\mathrm{R} \$$ 1,3 bilhão. Tais contratos foram firmados a uma taxa de juros média de 2,9\% a.a.; com um prazo de carência variável entre 0 e 30 meses (média de 18 meses), com prazo de amortização de até 102 meses.

Já o subprograma automático, no mesmo período, financiou capital de giro para duas empresas. Cada empresa tomou emprestado junto ao banco de fomento $\mathrm{R}$ \$15 milhões, a uma taxa de juros de 5,5\% a.a., com carência de seis meses e prazo de amortização de trinta meses (BNDES, 2014a).

Contudo, entende-se que apesar de ter ampliado as formas de apoio à cadeia de fornecedores - até então a participação do BNDES no fomento à IP\&G estava quase sempre associada aos financiamentos à Petrobras -, para alcançar os objetivos propostos, o banco necessita superar o limitado papel de fonte de concessão de financiamento.

\section{3 "postulado de coerência" aplicado à análise das Políticas de Desenvolvimento da Cadeia de Valor}

\subsection{Metodologia}

A análise das Políticas de Desenvolvimento da Cadeia de Valor, neste trabalho, tem como referência duas abordagens metodológicas, cujos métodos são utilizados de forma conjunta em virtude de suas complementariedades no que diz respeito ao tema tratado e aos objetivos que se deseja alcançar. Em primeiro plano, adotam-se as diretrizes fundamentais do "Postulado de Coerência" de Mário Testa" .

(14) O BNDES P\&G foi apresentado originalmente no Seminário "Desenvolvimento da Cadeia de Fornecedores de Petróleo e Gás" promovido pelo BNDES no dia primeiro de setembro de 2011 em seu auditório no Rio de Janeiro.

(15) Ver Testa $(1986,1987,1992)$. 
Considerando as características da pesquisa, o postulado traz como elemento fundamental a relação simultânea de determinação e condicionamento entre O-M-P (Organizações-Métodos-Propósitos).

Concebida originalmente para o estudo das políticas públicas direcionadas à área da saúde, no Brasil o método foi adotado em diferentes pesquisas no âmbito da Escola Nacional de Saúde Pública da Fiocruz (Fundação Oswaldo Cruz) ${ }^{16}$. No caso deste estudo o postulado foi adaptado à análise da política industrial.

Na esfera do "Postulado de Coerência", as Organizações representam a formalização da instituição, ou seja, a consolidação burocrática da organização que planeja e implementa a política. Os Métodos se configuram nas ferramentas à disposição do governo para planejar, viabilizar e implantar uma política. Por fim, os Propósitos são os objetivos de um governo para determinada política. Para Testa (1986), a "coerência" entre esses elementos no processo de planejamento e execução das políticas auxilia na análise da possibilidade de alcance dos resultados desejados.

No entanto, de forma complementar aos elementos referentes ao "Postulado de Coerência", faz-se uso de pontos da metodologia proposta por Bain \& Company e Tozzini Freire Advogados (2009) para o estudo de políticas de apoio ao desenvolvimento industrial e tecnológico. Neste sentido, adota-se as categorias "Objetivos" e "Ferramentas" - Propósitos e Métodos - utilizadas pelos autores para a análise das políticas de promoção da IP\&G no Brasil.

A partir da conjugação dos três componentes basilares do postulado de Testa (1986) com os pontos da metodologia de Bain \& Company e Tozzini Freire Advogados (2009), estruturou-se o Quadro 2, como referência para a análise das Políticas de Desenvolvimento da Cadeia de Valor para a IP\&G.

Quadro 2

Síntese dos elementos analisados na aplicação do "Postulado de Coerência" para o Desenvolvimento da Cadeia de Valor

\begin{tabular}{|c|c|c|c|}
\hline \multirow{6}{*}{ 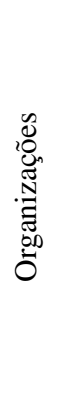 } & \multicolumn{2}{|r|}{ Propósitos } & $\begin{array}{l}\text { Promover o aumento da competitividade e da } \\
\text { participação das empresas nacionais no } \\
\text { mercado doméstico e internacional de } \mathrm{P} \& \mathrm{G} \text {. }\end{array}$ \\
\hline & \multirow{5}{*}{ Métodos } & Legislação & \\
\hline & & Regulamentação & \\
\hline & & Políticas do Executivo & \\
\hline & & Financiamento & \\
\hline & & Participação Estatal no Setor & \\
\hline & \multicolumn{3}{|c|}{$\begin{array}{l}1^{\mathrm{a}} \text { Fase - Foco na Cadeia de Valor } \\
2^{\mathrm{a}} \text { Fase - Foco no Conhecimento }\end{array}$} \\
\hline
\end{tabular}

Fonte: Elaboração própria a partir de Testa (1986, 1987 e 1992); Bain \& Company e Tozzini Freire Advogados (2009).

(16) Ver Giovanella (1989, 1990, 1991); Uribe Rivera (1995); Pitta (2001). 
A ideia é que os estudos da política industrial incorporem em suas análises aspectos referentes às instituições que desenvolvem e implantam a política - sua natureza, representatividade, competências, histórico, entre outros ${ }^{17}$. Neste contexto, as organizações planejadoras da ação pública devem, por sua vez, considerar a configuração da estrutura de mercado da indústria a que a política se destina. Entende-se que o desenho do mercado e o perfil das empresas que o compõem podem ser condicionantes importantes dos desdobramentos das ações propostas.

Além disso, torna-se relevante a avaliação dos métodos e ferramentas de execução das políticas - como, por exemplo, se há perspectiva de criação de regulação; alteração de legislação; linhas especiais de financiamento; intervenção estatal, entre outros ${ }^{18}$. Acredita-se que a conjugação coerente entre competências organizacionais e métodos de execução pode contribuir para a efetividade das metas estabelecidas pelos policy makers.

Por fim, entende-se ser necessário analisar a coerência dos propósitos aos quais essas políticas estão vinculadas e o alinhamento com as ferramentas de execução e com as capacitações das organizações condutoras das ações ${ }^{19}$. Nesse caso, tão importante quanto verificar se os propósitos da política estão em curso é também identificar se as metas estão em consonância com as demandas e com a agenda da indústria.

\subsection{Análise das políticas de desenvolvimento da cadeia de valor da IP\&G no Brasil}

\subsubsection{Organizações}

Uma das políticas mais relevantes dentre aquelas destinadas ao desenvolvimento da IP\&G no Brasil é o REPETRO. Lançado com o objetivo de sanar a escassez de oferta de máquinas e equipamentos para a cadeia da IP\&G, o regime tem como instituição gestora a Secretaria da Receita Federal (SRF) (ver Quadro 3).

(17) Conforme Nelson e Winter (2005), as estruturas organizacionais envolvidas na elaboração e na implantação das políticas são elementos críticos no processo de análise, uma vez que as políticas e os programas públicos são executados por organizações que devem aprender e se adaptar ao longo do processo. Desse modo, a formulação de uma boa política está diretamente relacionada ao desenho da estrutura organizacional, que deve ser capaz de ajustar seu comportamento em resposta ao aprendizado acumulado.

(18) Nelson e Winter (2005, p. 533) acreditam que "a forma de uma política é determinada em grande medida pela maneira de sua execução". Desse modo, os autores chamam a atenção para a natureza dos instrumentos utilizados na execução da ação pública e para como são determinantes para garantir o nível de interação necessário entre os atores envolvidos.

(19) Para Nelson e Winter (2005), a análise da política não tem poder de criar "um interesse público", mas pode verificar se a política apresenta compromissos sólidos para alcançar um propósito amplamente público. Os autores chamam a atenção para a importância da flexibilidade dos propósitos apresentados originalmente pelas políticas e programas. Assim, direções alternativas seriam fundamentais ao enfrentamento de desafios em um ambiente dinâmico, pois, nas palavras dos autores, "a elaboração de uma política é um processo evolucionário contínuo" (Nelson; Winter, 2005, p. 543). 
Quadro 3

Síntese das organizações responsáveis pelas políticas de desenvolvimento da cadeia de valor

\begin{tabular}{|c|c|c|c|}
\hline \multicolumn{4}{|c|}{ Desenvolvimento da Cadeia de Valor } \\
\hline \multirow{5}{*}{ Fatores } & \multicolumn{3}{|c|}{ Políticas/Ano de Implantação } \\
\hline & Repetro & $\begin{array}{c}\text { Política de } \\
\text { Conteúdo } \\
\text { Local }\end{array}$ & $\begin{array}{c}\text { Programa } \\
\text { BNDES } P \& G\end{array}$ \\
\hline & 1999 & 2003 & 2011 \\
\hline & \multicolumn{3}{|c|}{ Organizações } \\
\hline & Secretaria da Receita Federal & ANP & BNDES \\
\hline Natureza; & Pública & Autarquia & Pública \\
\hline $\begin{array}{l}\text { Abrangência } \\
\text { territorial; }\end{array}$ & Nacional & Nacional & Internacional \\
\hline Ano de Criação & 1968 & 1998 & 1952 \\
\hline Representatividade. & União & $\begin{array}{c}\text { União, } \\
\text { Sociedade } \\
\text { Civil e Atores } \\
\text { da IP\&G }\end{array}$ & União \\
\hline $\begin{array}{c}\text { Competências/Missão, } \\
\text { Visão e Valores }\end{array}$ & 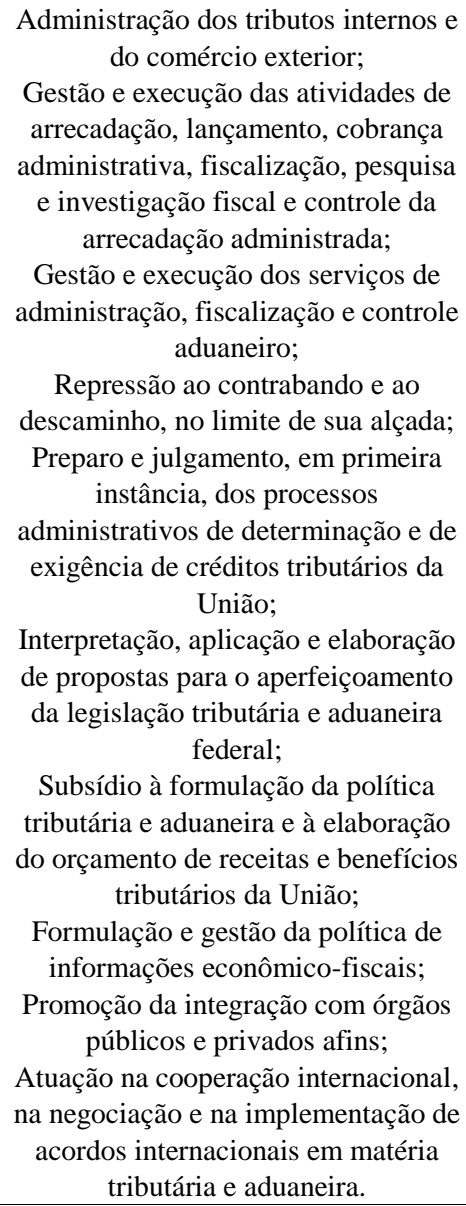 & $\begin{array}{c}\text { Estabelecer as } \\
\text { resoluções e } \\
\text { instruções } \\
\text { normativas } \\
\text { para o } \\
\text { funcionamento } \\
\text { da IP\&G; } \\
\text { Outorgar } \\
\text { autorizações } \\
\text { para as } \\
\text { atividades dos } \\
\text { setores } \\
\text { regulados; } \\
\text { promover } \\
\text { licitações e } \\
\text { assinar } \\
\text { contratos em } \\
\text { nome da União } \\
\text { com os } \\
\text { concessionários } \\
\text { em E\&P; } \\
\text { Verificar o } \\
\text { cumprimento } \\
\text { das normas nas } \\
\text { atividades dos } \\
\text { setores } \\
\text { regulados. }\end{array}$ & $\begin{array}{c}\text { Promover o } \\
\text { desenvolvimento } \\
\text { sustentável e } \\
\text { competitivo da } \\
\text { economia } \\
\text { brasileira, com } \\
\text { geração de } \\
\text { emprego e } \\
\text { redução das } \\
\text { desigualdades } \\
\text { sociais e } \\
\text { regionais; } \\
\text { Ser o Banco do } \\
\text { desenvolvimento } \\
\text { do Brasil, } \\
\text { instituição de } \\
\text { excelência, } \\
\text { inovadora e } \\
\text { proativa ante aos } \\
\text { desafios da nossa } \\
\text { sociedade; } \\
\text { Valores } \\
\text { Ética } \\
\text { Compromisso } \\
\text { com o } \\
\text { desenvolvimento; } \\
\text { Espírito público; } \\
\text { Excelência; }\end{array}$ \\
\hline
\end{tabular}

Fonte: Elaboração própria a partir de ANP (2012), BNDES (2015) e Receita Federal (2015). 
A SRF é um órgão subordinado ao Ministério da Fazenda que tem entre suas competências: subsidiar a formulação da política tributária e aduaneira, e; promover a gestão e a execução dos serviços de administração, fiscalização e controle aduaneiro. Neste sentido, a SRF apresenta os requisitos necessários para realizar o controle administrativo do regime.

Uma síntese contrária ao Repetro, a Política de Conteúdo Local, tem como organização responsável por sua aplicação a ANP. A agência reguladora que incluiu, a partir da quinta rodada, a obrigatoriedade de CL mínimo nos contratos de licitação tem sido constantemente questionada em relação a sua competência. Nesse sentido, a agência reguladora não teria condições estruturais e técnicas para fiscalizar o cumprimento dessa cláusula (ver Quadro 3).

Por fim, entre as organizações responsáveis pelas políticas de Desenvolvimento da Cadeia de Valor abordadas neste trabalho, está o BNDES. O banco de desenvolvimento brasileiro é uma referência internacional de capacidade de fomento à atividade produtiva, no entanto, apenas em 2010 criou o Departamento da Cadeia Produtiva de Petróleo e Gás. Até então, a atuação do BNDES junto a IP\&G se limitava, quase que exclusivamente, ao fomento de projetos da Petrobras.

Em consequência da natureza de sua atuação, entre 1997 e 2011, apenas cinco fornecedores da Cadeia de P\&G - Lupatech, Mipel, Steelinject, Prysmian e Ruhrpmpen - tiveram projetos contratados pelo BNDES em operações não automáticas. A somatória do valor financiado a essas empresas foi de $\mathrm{R} \$ 1.204 .661 .042,00^{20}$.

\subsubsection{Métodos}

De acordo com a referência adotada, as políticas para o campo de Desenvolvimento da Cadeia de Valor contemplam a possibilidade de utilização das cinco ferramentas apontadas pela metodologia - Legislação, Regulamentação, Políticas do Executivo, Financiamento e Participação Estatal no Setor. No entanto, entende-se que o Repetro, a Política de Conteúdo Local e o BNDES P\&G se enquadram em apenas três: Regulamentação, Políticas do Executivo e Financiamento (Quadro 4).

Nesse sentido, tanto o Repetro quanto a Política de Conteúdo Local, explicitamente lançam mão da Regulamentação como instrumento de política industrial. Entretanto, deveria ser introduzida em uma segunda fase de desenvolvimento da indústria, sobretudo depois de consolidadas as políticas de Estruturação Física e Institucional ${ }^{21}$. Além disso, deveriam ser constituídas por

(20) Ver BNDES (2014b).

(21) Ver Bain \& Company e Tozzini Freire Advogados (2009). 


\subsubsection{Propósitos}

Com relação ao elemento Propósitos, percebe-se que as três políticas apresentadas consideram em suas diretrizes o objetivo apontado pela metodologia para esse campo, ou seja, têm como objetivo promover o aumento da competitividade e da participação das empresas nacionais na cadeia da IP\&G.

No caso do Repetro, ao permitir que as empresas dos segmentos de exploração tenham acesso a equipamentos necessários ao início das atividades de pesquisa, que pode culminar na descoberta de novos campos exploratórios, garante de forma indireta a demanda por bens e serviços complementares ofertados por empresas nacionais que atuam em elos posteriores da cadeia.

Um dos fatos relacionados à IP\&G nacional na última década, imputado ao Repetro, foi o aumento significativo das reservas provadas a partir da adoção do regime, justificado pelo incremento da capacidade de pesquisa e exploração de novos campos exploratórios proporcionados pelo programa. Portanto, uma questão relevante do debate passa pela capacidade da oferta nacional de atender à demanda nos demais elos da cadeia.

Já no caso da Política de Conteúdo Local, como se trata de um item compulsório, não há questionamento em relação ao aumento da participação das empresas nacionais no mercado doméstico da IP\&G. Como pode ser observado no gráfico 6, a seguir, a ocorrência de CL apresentado pelas OCs nos processos licitatórios aumentou substancialmente a partir da adoção da política.

\section{Gráfico 6}

Conteúdo local médio nas etapas de exploração e desenvolvimento Rodadas 1 a $12^{(*)}$

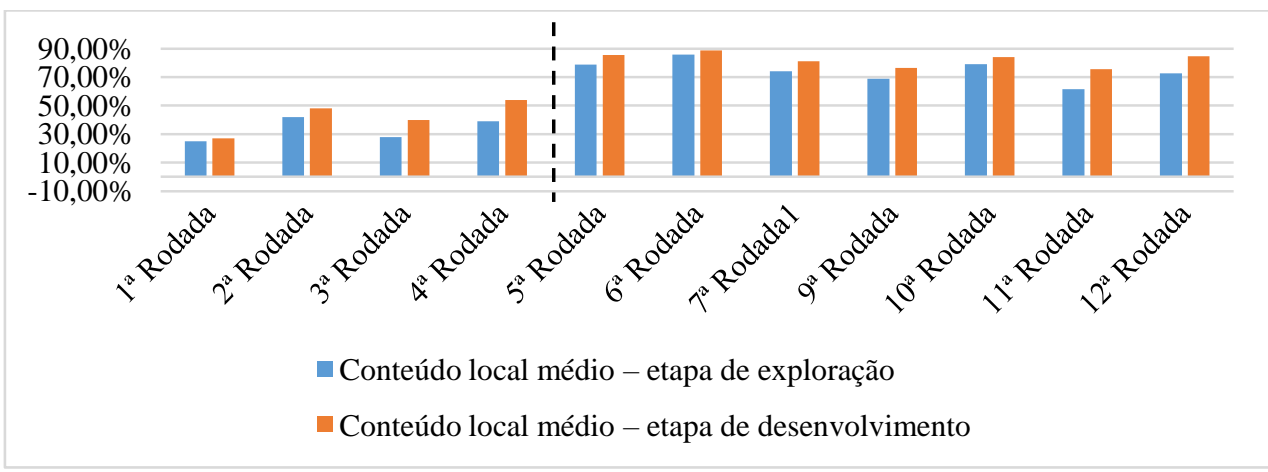

(*) A oitava rodada não foi finalizada até o momento.

Fonte: Elaboração própria a partir de ANP (2014).

O Programa BNDES P\&G, a mais recente entre as três políticas consideradas, também contempla o objetivo apontado pela metodologia. Mais do 
que isso, o programa propôs enfrentar uma série de desafios colocados à IP\&G nacional ao longo das últimas décadas como, por exemplo, apoiar: (i) o desenvolvimento da capacidade para empreender atividades inovativas; (ii) os projetos de inovação de natureza tecnológica, e; (iii) os investimentos necessários à absorção dos resultados do processo de pesquisa e desenvolvimento ou inovação. No entanto, como exposto anteriormente, as fragilidades da cadeia da IP\&G não se limitam ao acesso a recursos para investimento.

\subsubsection{Discussão dos resultados}

As políticas consideradas para o campo de Desenvolvimento da Cadeia de Valor representam, para a moderna fase da IP\&G no Brasil, avanços importantes e limites bastante claros em relação às necessidades postas por esse mercado.

Com relação ao Repetro, entende-se que, em última instância, a adoção do regime representa a abertura de uma brecha na legislação tributária brasileira que facilita a importação de equipamentos adquiridos no exterior, sob o regime de admissão temporária. Assim, os bens de origem nacional - sobre os quais incidem IPI, ICMS, PIS e Cofins - ficam em situação de desvantagem competitiva, com tributação em torno de $35 \%$, contra carga a tributária "zero" incidente sobre os importados (Rappel, 2003).

Nesse sentido, De Oliveira e Rocha (2006) apontam que o Repetro apresenta duas grandes dificuldades. A primeira é a dificuldade em desonerar toda a cadeia produtiva. Para os autores, os problemas se iniciam com o fato dos fornecedores da cadeia estarem distribuídos em diversos estados da federação, criando barreiras de distintas naturezas para a isenção do ICMS. A segunda dificuldade é a complexidade da legislação. As engenharias tributárias realizadas, e interpretações contraditórias da legislação, geram incertezas na obtenção de isenções, além de criarem pendências cuja solução demanda tempo e recursos caros às empresas.

Para Araújo, Mendes e Costa (2012), mais de uma década após a instituição do regime, fica nítido que o Repetro se limitou a alguns elos da cadeia. Como consequência, aponta-se o benefício de forma direta às operadoras, uma vez que essas deixaram de recolher tributos em virtude da modalidade de admissão temporária. Além das operadoras, empresas do primeiro elo da cadeia se beneficiam do regime especial, a partir da utilização do instrumento de exportação ficta associada ao drawback ${ }^{22}$.

(22) "Essas empresas exportam fictamente seus produtos para uma empresa no exterior, subsidiária da operadora que se encontra no país, e esta, por sua vez, retorna também fictamente esse bem por meio da admissão temporária. As demais empresas em elos mais distantes da cadeia, por não contarem com acesso aos instrumentos do Repetro, acabam enfrentando maiores custos, uma vez que precisam recolher os tributos internos federais e estaduais, e, como consequência, elevando os preços finais de seus produtos" (Araújo; Mendes; Costa, 2012, p. 234). 
É reconhecido que o Repetro contribuiu para desonerar investimentos na indústria de petróleo e gás. Também é inegável a importância do regime na redução dos custos e na promoção da competitividade das grandes operadoras. Mas, sem perder de vista as limitações promovidas pelo regime, sobretudo na criação de desvantagem competitiva para as empresas dos elos mais periféricos da cadeia da IP\&G, ou seja, empresas brasileiras de pequeno e médio portes.

Assim como o Repetro, a Política de Conteúdo Local divide opiniões em relação aos benefícios promovidos para uma inserção das empresas nacionais na cadeia da IP\&G em bases competitivas. De acordo Zylbersztajn e Agel (2013), adoção do critério de CL obrigatório no procedimento licitatório da ANP é contraditório por tratar da importância de estimular a indústria nacional e, ao mesmo tempo, ignorar sua incapacidade de gerar bens e serviços capazes de atender à demanda do setor de E\&P.

(...) até os dias de hoje há controvérsias quanto à aptidão da indústria nacional de bens e serviços para atender à demanda do setor de exploração e produção nos altos índices comprometidos pelos concessionários. A maior queixa dos concessionários é que a obrigação imposta pelo governo federal para proteger a indústria local acabou por torna-la mais cara do que seus concorrentes internacionais (Zylbersztajn; Agel, 2013, p. 68).

Para De Oliveira (2008), parte da solução para essas questões está na convergência de políticas industriais com políticas de capacitação tecnológica. Para o autor, no caso brasileiro, não existe alinhamento entre a política industrial e a política tecnológica porque ambas possuem focos mal definidos. Além disso, a política de compras da Petrobras estaria muito vinculada à ideia de substituição de importações e de ocupação do mercado interno a partir da fabricação local.

Essa política não prioriza especializações produtivas apoiadas em vantagens competitivas. Ela não associa conteúdo local, com desenvolvimento tecnológico endógeno. As relações entre a Petrobras e os fornecedores nacionais se limitam às exigências de satisfazer os índices de nacionalização, mas não almejam o desenvolvimento de vantagens competitivas (De Oliveira, 2008, p. 101).

Desse modo, mesmo que a Política de Conteúdo Local tenha contribuído para o aumento significativo da participação das empresas domésticas na cadeia da IP\&G, não foi capaz de promover os avanços necessários em produtividade e inovação exigidos pelo mercado.

Complementar a isso, as alterações das regras de CL - mínimo e máximo -, bem como das penalizações pelo não cumprimento dos contratos, dificultam o planejamento de longo prazo das empresas do setor. Aliado a essa questão, o alto custo de certificação do CL onera o investimento produtivo e faz com que a política enfrente resistência por parte das OCs. Portanto, a Política de Conteúdo Local precisa ser complementada por ações direcionadas aos avanços técnicos, científicos e inovativos necessários ao atendimento das demandas dessa indústria. 
Na busca por uma alternativa a esse problema, foi lançado o Programa BNDES P\&G. No entanto, como pode ser observado no Quadro 5, o programa ficou limitado a um número restrito de empresas, distante da proposta de facilidade de acesso ao crédito pelas MPMEs, presente nos objetivos originais do programa.

Quadro 5

Síntese dos Contratos Firmados pelo Programa BNDES P\&G (2012-05/2014)

\begin{tabular}{|c|c|c|c|c|c|c|}
\hline Nome do Cliente & $\begin{array}{l}\text { País de } \\
\text { Origem }\end{array}$ & $\begin{array}{c}\text { Número } \\
\text { de } \\
\text { Contratos }\end{array}$ & $\begin{array}{c}\text { Valor Total } \\
\text { Contratado }(\mathrm{R} \$)\end{array}$ & $\begin{array}{l}\text { Prazo Médio } \\
\text { Amortização } \\
\text { (meses) }\end{array}$ & $\begin{array}{c}\text { Prazo Médio } \\
\text { de Carência } \\
\text { (meses) }\end{array}$ & $\begin{array}{c}\text { Taxa de } \\
\text { Juros } \\
\text { Média } \\
\text { (ao ano) }\end{array}$ \\
\hline $\begin{array}{l}\text { Aker Solutions } \\
\text { do Brasil Ltda. }\end{array}$ & Noruega & 3 & $263.128 .670,00$ & 74 & 22 & 1,93 \\
\hline $\begin{array}{c}\text { Altus Sistemas } \\
\text { de Automação } \\
\text { S/A }\end{array}$ & Brasil & 4 & $51.800 .000,00$ & 32 & 14 & 3,00 \\
\hline $\begin{array}{c}\text { Belov } \\
\text { Engenharia Ltda. }\end{array}$ & Brasil & 1 & $15.000 .000,00$ & 30 & 6 & 5,00 \\
\hline $\begin{array}{c}\text { Brasco Logística } \\
\text { Offshore Ltda. }\end{array}$ & Brasil & 5 & $109.469 .541,00$ & 80 & 20 & 2,05 \\
\hline $\begin{array}{l}\text { Flexibras Tubos } \\
\text { Flexíveis Ltda. }\end{array}$ & França & 2 & $303.997 .000,00$ & 96 & 24 & 2,68 \\
\hline Georadar S/A & Brasil & 3 & $143.000 .000,00$ & 48 & 12 & 4,50 \\
\hline $\begin{array}{l}\text { Jotun Brasil } \\
\text { Importação, } \\
\text { Export e Ind de } \\
\text { Tintas Ltda. }\end{array}$ & Noruega & 1 & $57.122 .000,00$ & 72 & 24 & 1,80 \\
\hline $\begin{array}{c}\text { Metasa Óleo e } \\
\text { Gás Ltda. }\end{array}$ & Brasil & 3 & $23.050 .453,17$ & 84 & 12 & 4,07 \\
\hline $\begin{array}{c}\text { Odebrecht Óleo } \\
\text { e Gás S/A }\end{array}$ & Brasil & 4 & $24.793 .109,00$ & 37 & 23 & 2,85 \\
\hline $\begin{array}{l}\text { Pronto Express } \\
\text { Logística Ltda. }\end{array}$ & Brasil & 1 & $15.000 .000,00$ & 30 & 6 & 5,50 \\
\hline $\begin{array}{l}\text { Rossini Murta } \\
\text { Indústria } \\
\text { Metalúrgica } \\
\text { Ltda. }\end{array}$ & Brasil & 1 & $900.000,00$ & 102 & 18 & 3,37 \\
\hline $\begin{array}{c}\text { Techint } \\
\text { Engenharia e } \\
\text { Construção S/A }\end{array}$ & Itália & 3 & $309.677 .000,00$ & 67 & 30 & 1,93 \\
\hline $\begin{array}{c}\text { Vallourec Tubos } \\
\text { do Brasil S/A }\end{array}$ & França & 1 & $51.661 .000,00$ & 96 & 24 & 1,40 \\
\hline \multirow[t]{2}{*}{$\begin{array}{c}\text { Villares Metals } \\
\text { S/A } \\
\end{array}$} & Brasil & 2 & $18.001 .193,00$ & 78 & 18 & 1,80 \\
\hline & & 34 & $\begin{array}{c}1.386 .599 .966,1 \\
7\end{array}$ & 69 & 18 & \\
\hline
\end{tabular}

Fonte: Elaboração própria a partir de BNDES (2014a). 
Apenas quatorze empresas, a partir de 34 contratos, financiaram mais de R \$ 1,38 bilhão. Uma concentração bastante significativa de recursos em empresas de médio e grande porte, a partir de operações com longos prazos de carência e amortização, e taxas de juros atrativas para o mercado brasileiro. Contudo, o que mais chama a atenção é que apenas quatro empresas - Aker, Flexibras, Georadar e Techint Engenharia, capturaram mais de $70 \%$ do valor financiado no período estudado.

Portanto, mesmo que os propósitos apresentados pelo Programa BNDES $P \& G$ atendam às diretrizes da metodologia adotada neste trabalho, o programa não conseguiu, em seus anos iniciais, cumprir com tais objetivos. Assim, é possível afirmar que tanto o Repetro, quanto a Política de Conteúdo Local e o Programa BNDES P\&G, apresentam avanços e limites em relação ao Desenvolvimento da Cadeia de Valor da IP\&G, sendo os Métodos de implantação das políticas os principais responsáveis pelas limitações observadas.

\section{Considerações finais}

A Indústria de Petróleo e Gás Natural foi responsável por elevar o debate de política energética para além das questões relacionadas à capacidade de oferta de combustível e aos fatores de produção.

No caso do Brasil, o esforço de desenvolvimento desse setor ficou a cargo do Estado, a partir do exercício do monopólio estatal, materializado na atuação da Petrobras. Nesse contexto, ciente da relevância crescente dessa indústria, o Estado entendeu que seria importante aproveitar as vantagens locacionais de empresas brasileiras para dar impulso a uma cadeia de fornecedores no país. Assim, a partir dos anos de 1970, a participação de empresas brasileiras em diferentes elos da cadeia de fornecedores passou a ser cada vez mais comum.

Contudo, é importante ressaltar que ao longo das décadas seguintes, mesmo com uma presença maior de fornecedores locais, não houve regularidade na participação desses fornecedores nos empreendimentos da Estatal. Em que pese, ao longo do período do monopólio estatal, o patente desenvolvimento de uma cadeia local, com capacitações técnicas, tecnológicas e de recursos humanos, sobretudo, na produção offshore em águas profundas, historicamente, jamais exerceu protagonismo absoluto no fornecimento de bens e serviços à Petrobras.

O fim do monopólio estatal nos anos de 1990 deixou ainda mais evidente a fragilidade das empresas nacionais da cadeia da IP\&G. Frente à nova realidade de volume de investimentos e demanda por bens e serviços especializados, os fornecedores locais foram incapazes de garantir a oferta necessária ao desenvolvimento das atividades de E\&P no país. Desse modo, o que se viu foi a reprodução em escala nacional do domínio da cadeia por empresas estrangeiras, 
líderes mundiais em seus segmentos. Com o intuito de minimizar essa disparidade, foram lançadas bases para a construção de políticas voltadas ao Desenvolvimento da Cadeia de Valor da IP\&G.

Ao longo deste trabalho buscou-se apresentar essas políticas com o intuito de desvendar quais os motivos levam a que, ainda hoje, as empresas brasileiras representem, na maior parte dos segmentos e subsegmentos, papel secundário nessa indústria. Mais do que isso, por que essas políticas não são capazes de fazer com que os "Propósitos" apontados para o desenvolvimento da cadeia de fornecedores sejam alcançados.

Desse modo, entende-se que a reflexão referente aos problemas de desenvolvimento da Cadeia Nacional da IP\&G no Brasil passa pela configuração da estrutura de mercado do setor e pela análise das políticas a partir da relação entre OM-P.

A estrutura de mercado apresentada na primeira seção evidencia particularidades que fazem da cadeia da IP\&G um segmento com altos níveis de exigência para as empresas que desejam realizar sua inserção em bases competitivas. Dessa forma, essa configuração de mercado, ao mesmo tempo em que cria as condições para a expansão dos investimentos e da participação das empresas brasileiras, também representa o cenário para a manutenção da estrutura de mercado vigente.

Com relação à análise das Políticas de Desenvolvimento da Cadeia de Valor a partir dos componentes O-M-P, entende-se que as maiores fragilidades estão nos Métodos de elaboração e implantação das ações públicas. No caso do Repetro, apesar de promover reconhecidos avanços no segmento de E\&P, o regime se mostrou muito mais excludente e seletivo do que dinamizador das empresas nacionais da cadeia.

Já a Política de Conteúdo Local, contraditoriamente, uma reação ao Repetro, apresentou-se de forma inconstante ao longo dos últimos dez anos, com alterações de regras que dificultam o planejamento das OCs e desconsideram a fragilidade das empresas nacionais em atender aos requisitos dos planos de investimento, o que atrasa e onera os projetos do setor.

Ainda nesse campo, o Programa BNDES P\&G se apresenta apenas como mais uma alternativa de financiamento de projetos de investimento. Concentrando suas ações em um número pequeno de empresas, o programa tem dificuldades para cumprir com os propósitos apresentados em sua origem. Nesse sentido, o próprio BNDES admite que é necessário um envolvimento maior do banco em outras atividades da cadeia para que os recursos empregados deem os resultados esperados. 
A partir das análises feitas ao longo deste trabalho, associadas às considerações realizadas nesta seção, confirma-se a hipótese de que o desenho complexo da estrutura de mercado desse setor, associado a uma frágil coordenação entre O-M-P, cria obstáculos ao desenvolvimento e à implantação de políticas públicas capazes de promover o aumento da competitividade e da participação das empresas nacionais na cadeia da IP\&G.

Portanto, as fragilidades das políticas de apoio às empresas nacionais da cadeia da IP\&G estão relacionadas ao baixo nível de coordenação entre a leitura correta do desenho da estrutura de mercado pela organização que planeja e implementa a política e a seleção dos métodos adequados para os propósitos desejados.

\section{Referências}

ANP - Agência Nacional do Petróleo, Gás Natural e Biocombustíveis. Portaria ANP, n. 69. In: Coleção de Bolso Agências Reguladoras. São Paulo: Lex Magister, 2012.

ANP - Agência Nacional do Petróleo, Gás Natural e Biocombustíveis. Anuário estatístico brasileiro do petróleo, gás natural e biocombustíveis: 2013. Rio de Janeiro: ANP, 2014.

ARAÚJO, B. P.; MENDES, A. P. A.; COSTA, R. C. Perspectivas para o desenvolvimento industrial e tecnológico na cadeia de fornecedores de bens e serviços relacionados ao setor de P\&G. In: SOUSA, F. L. (Org.). BNDES 60 anos: perspectivas setoriais. Rio de Janeiro: BNDES, 2012. v.1.

BAIN, J. Barries to new competition. Cambridge: Harvard University Press, 1956.

BAIN \& COMPANY; TOZZINI FREIRE ADVOGADOS. Estudos de alternativas regulatórias institucionais e financeiras para a exploração e produção de petróleo e gás natural e para o desenvolvimento industrial da cadeia produtiva de petróleo e gás no Brasil. 1. ed. São Paulo: Bain \& Company e Tozzini Freire Advogados, 2009.

BAPTISTA, M. A. C. Política industrial: uma interpretação heterodoxa. Tese (Doutorado)-Programa de Pós-Graduação, Instituto de Economia da Universidade Estadual de Campinas - Unicamp, Campinas, 2000.

BNDES - Banco Nacional de Desenvolvimento Econômico e Social. Operações contratadas pelo sistema BNDES no âmbito do programa BNDES P\&G. Planilha de banco de dados. Rio de Janeiro: BNDES, 2014a. 
BNDES - Banco Nacional de Desenvolvimento Econômico e Social. Operações contratadas pelo sistema BNDES na Cadeia da IP\&G: 1997-2011. Planilha de banco de dados. Rio de Janeiro: BNDES, 2014b.

BNDES - Banco Nacional de Desenvolvimento Econômico e Social. Missão, visão $e$ valores. Rio de Janeiro: BNDES, 2015. Disponível em: https://wwwh.bndes.gov.br/SiteBNDES/bndes/bndes_pt/Institucional/O_BNDES/A_Empresa/ missao visao valores.html. Acesso em: 12 mar. 2015.

CIMOLI, M. et al. Institutions and policies shaping industrial development: an introductory note. In: Industrial policy and development: the political economy of capabilities accumulation. Oxford, United Kingdom: Oxford University Press, 2009.

DE NEGRI, J. A. (Coord.). Poder de compra da Petrobras: impactos econômicos nos seus fornecedores. Brasília: Ipea, 2011.

DE OLIVEIRA, A. (Coord.). Indústria para-petrolifera brasileira: competitividade, desafios e oportunidades. Rio de Janeiro: Prominp, 2008.

DE OLIVEIRA, A.; ROCHA, F. Estudo da competitividade da indústria brasileira de bens e serviços do setor de $P \& G$ - conclusões e recomendações de política. Rio de Janeiro: Prominp, 2006.

DUNNING, J. H. The globalization of business: the challenge of the 1990s. London: Routledge, 1993.

FERNÁNDEZ Y FERNÁNDEZ, E. Indústria nacional de bens e serviços nos arranjos produtivos do setor de óleo e gás natural no Brasil. In: GIAMBIAGI, F.; LUCAS, L. P. V. (Org.). Petróleo - reforma e contrarreforma do setor petrolífero brasileiro. Rio de Janeiro: Elsevier, 2013.

FERRAZ, J. C.; DE PAULA, G. M.; KUPFER, D. Política Industrial. In: KUPFER, D.; HASENCLEVER, L. (Org.). Economia industrial: fundamentos teóricos e práticas no Brasil. Rio de Janeiro: Elsevier, 2002.

GILBERT, R. Mobility barriers and the value of incumbency. In: SCHMALENSEE, R.; WILLIG, R. (Ed.). Handbook of industrial organization. Rio de Janeiro: Elsevier, 1989. v. 1.

GIOVANELLA, L. Ideologia e poder no planejamento estratégico em saúde: uma discussão da abordagem de Mário Testa. Dissertação (Mestrado)-Programa de PósGraduação em Saúde Pública, Escola Nacional de Saúde Pública, Rio de Janeiro, 1989.

GIOVANELLA, L. Planejamento estratégico em saúde: uma discussão da abordagem de Mário Testa. Cadernos de Saúde Pública, Rio de Janeiro, v. 6, n. 2, jun. 1990. 
GIOVANELLA, L. As origens e as correntes atuais do enfoque estratégico em planejamento de saúde na América Latina. Cadernos de Saúde Pública, Rio de Janeiro, v. 7, n. 1, p. 26-44, mar. 1991. Disponível em <http://www.scielo.br/scielo.php?script=sci_arttext\&pid=S0102-

$\underline{311 X 1991000100004 \& \operatorname{lng}=e n \& n r m=i s o}>$. Acesso em: 7 nov. 2017.

HITT M., A.; DUANE, I. R.; ROBERT, E. H. Strategic management: competitiveness and globalization. SouthWestern: Thomson, 2005.

MALERBA, F. Sectoral system and innovation and technology policy. Revista Brasileira de Inovação, v. 2, n. 2, 2003.

MOREIRA, M. M.; CORRÊA, P. G. Abertura comercial e indústria: o que se pode esperar e o que se vem obtendo. Revista de Economia Política, São Paulo, v. 17, n. 2 (66), abr./jun. 1997.

NELSON, R. R.; WINTER, S. G. Uma teoria evolucionária da mudança econômica. Campinas: Editora Unicamp, 2005.

OGFJ - Oil and Gas Finacinal Journal. Mergers \& Acquisitions Deal Monitor 2015. Disponível em: http://www.ogfj.com/mergers-acquisitions/deal-monitor.html. Acesso em: 15 jan. 2015.

PENROSE, E. T. A teoria do crescimento da firma. Campinas: Editora Unicamp, 2006.

PITTA, A. M. R. Comunicação, promoção da saúde e democracia: políticas e estratégias de comunicação no Sistema Único de Saúde no Brasil. Tese (Doutorado)-Escola de Comunicação. Universidade Federal do Rio de Janeiro, Rio de Janeiro, 2001.

RAPPEL, E. Oportunidades e desafios do parque nacional de fornecedores de bens e serviços para o setor de petróleo e gás. In: PIQUET, Rosélia (Org.). Petróleo, royalties e região. Rio de Janeiro: Garamond Universitária, 2003.

RAPPEL, E. Tendências do setor de petróleo e gás no Brasil: oportunidades e desafios para os fornecedores de bens e serviços. In: PIQUET, Rosélia; SERRA, Rodrigo (Org.). Petróleo e região no Brasil: o desafio da abundância. Rio de Janeiro: Garamond Universitária, 2007.

RECEITA FEDERAL. Regimes aduaneiros especiais/Repetro. Brasília: Secretaria da Receita Federal do Brasil, Ministério da Fazenda, 2014. Disponível em: http://idg.receita.fazenda.gov.br/orientacao/aduaneira/manuais/repetro/topicos.

Acesso em: 2 jan. 2015.

RECEITA FEDERAL. Competências da Receita Federal. Brasília: Secretaria da Receita Federal do Brasil, Ministério da Fazenda, 2015. Disponível em: 
http://idg.receita.fazenda.gov.br/sobre/institucional/competencias-1. Acesso em: 10 mar. 2015.

ROSENBERG, N. Por dentro da caixa-preta: tecnologia e economia. Campinas: Editora da Unicamp, 2006.

STEINDL, J. Maturidade e estagnação no capitalismo americano: com uma nova introdução do autor. São Paulo: Abril Cultural, 1983.

TEECE, D.; PISANO, G. The dynamic capabilities of firms: an introduction. Industrial and corporate change, v. 3, n. 3, p. 537-556, 1994.

TESTA, M. Estrategia, coherencia y poder en las propuestas de salud. Cuadernos Médico-Sociales. Rosario, n. 38 (1 $1^{\mathrm{a}}$ parte); n. 39 (2ªrte), 1987.

TESTA, M. Pensamiento estrategico, lógica de programación, estrategia y programación. Buenos Aires [s.n.] 1986. Mimeografado.

TESTA, M. Pensar em saúde. Porto Alegre: Artes Médicas, 1992.

TIGRE, P. Inovação e teorias da firma em três paradigmas. Revista de Economia Contemporânea, n. 3, 1998.

URIBE-RIVERA, F. J. Agir comunicativo e planejamento social: uma crítica ao enfoque estratégico. Rio de Janeiro: Fiocruz, 1995.

ZYLBERSZTAJN, D.; AGEL, S. A reforma do setor de petróleo de 1997: racionalidade, concepção e implantação. In: GIAMBIAGI, F.; LUCAS, L. P. V. (Org.). Petróleo - reforma e contrarreforma do setor petrolífero brasileiro. Rio de Janeiro: Elsevier, 2013. 